\title{
Chapter 27 \\ The Future of Hybrid Electric Vehicles and Sustainable Vehicles in the UK
}

\author{
Greg Last, David E. Agbro, and Abhishek Asthana
}

\begin{abstract}
This paper details the development of the hybrid electric vehicle (HEV) and its integration into the UK market. The aim of this research was to explore the benefits and limitations of the HEV system which there are many. Government policies and incentives; both current and future as well as HEV technologies are also summarised. The HEV is an excellent short to medium term solution for making travel more sustainable. However, in the long term, push for electric vehicles (EVs) will significantly increase from the Government in its aim to meet stringent emissions policies and there will likely be legislation to phase out HEVs that cannot be plugged in.
\end{abstract}

Keywords Hybrid electric vehicles $\cdot$ Sustainable travel $\cdot \mathrm{CO}_{2}$ emissions $\cdot$ Electric vehicles $\cdot$ Government policies

\subsection{Introduction}

With the current climate crisis facing the world, there is a big push for countries to reduce their carbon emissions and lower the levels of air pollution affecting human health. In the UK, a large contributor to air pollution and climate change is the transport sector, responsible for around $24 \%$ of total UK emissions [1]. Transportation includes travel by Air, Water and Road, with road transportation accounting for $72 \%$ of the $\mathrm{CO}_{2}$ emissions. The automobile makes up the largest proportion of the road transport, at around 61\% [2] and holds the opportunity to significantly improve the UK's total carbon emission. Reducing tailpipe emissions is hugely important for the planet and human health.

This report aims to provide useful and current information on the status of HEVs in the UK, specifically the benefits and pitfalls from both a performance and environmental angle. Government policies and incentives; both current and future as well as HEV technologies are outlined. The report will make for an easier understanding

G. Last · D. E. Agbro $(\bowtie) \cdot$ A. Asthana

Sheffield Hallam University, Howard St, Sheffield S1 1WB, UK

e-mail:d.agbro@shu.ac.uk 
Fig. 27.1 $\mathrm{CO}_{2}$ Emission contributions from each transport mode in the UK as of 2016 [2]

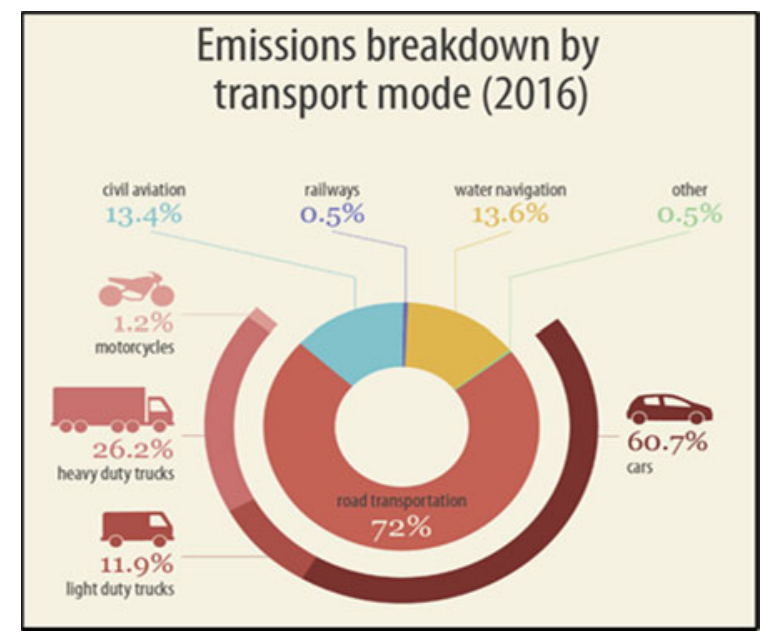

of all aspects of owning an HEV in the UK, whereby an informed decision can be made on whether an HEV is suitable for the individual, or not (Fig. 27.1).

\subsection{Mainstream Integration of HEV's in UK}

The first popular HEV to hit a consumer market was the Toyota Prius in Japan, in 1997. 18,000 were sold in the first year and two years later, the Honda Insight was launched, available in Japan and the US. The Prius shortly followed and was lauched in the US, Europe and the rest of the world in 2000 [3]. These two cars marked the start of the large scale production of HEV's across the Globe. In 1999 Honda sold around 200 Insight's making the model the first actual HEV sold commercially in the UK [4]. With such low number of Honda Insight's bought, the Toyota Prius has become generally accepted as the first HEV on the UK market in 2000 and became the world's top selling HEV_-in 2017 Toyota had sold 4 million units globally [3]. The Prius marked the start of commercial HEV's as a viable choice available for the consumer in the UK. The economic advantages of a hybrid became instantly obvious to the more frugal consumer. With the initial version of the Toyota Prius, owners could expect a combined $60 \mathrm{mpg}$ compared to the Toyota Corolla, a similar 4 door petrol Internal Combustion Engine (ICE) vehicle with an average combined 31mpg [5]. This comparison is true for most ICE-HE vehicles with the fuel economy been far better in the latter. Over the last two decades, the HEV has developed with more and more manufacturers offering a HEV in their range. Many of these models have been available in the UK market, however the Prius has remained at the top of the list with the UK being one of the leading EU markets for the model since 2000, taking $20 \%$ of Prius sales by 2010 [6]. Although the UK has been a seemingly big advocate of the HEV, the market share of HEV's across the total automotive market 
Fig. 27.2 Market share of non-ICE automobiles in the UK from 2010-2015 [8]

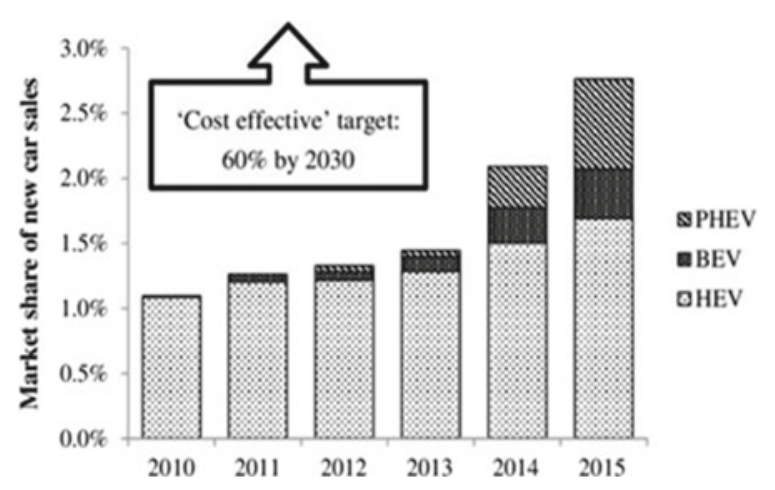

has been quite small by proportion; in 2010 just $1.1 \%$ of all automobile sales were HEV's and by 2015 that had only risen to $1.6 \%$ [7]. Figure 27.2 shows the shares of non-ICE automobiles in the UK including plug-in hybrid electric vehicle (PHEV), battery electric vehicle (BEV) and hybrid electric vehicles (HEV).

However, the market share is on the rise, as is the demand for HEV's, and as of October 2019, $10 \%$ of the market is now held by alternate fuel vehicles, including $5.5 \%$ HEV's [9]. This shows that both consumer and manufacturer are making a step in the right direction for sustainable travel. For the consumer, the environmental impact of driving an ICE vehicle is a consideration but with the cost of fuel rising and the economic climate in the UK still unsettled, the demand for lower fuel consumption is a big driver of sales of HEV's. So, the HEV like the Toyota Prius, or similar offerings from Honda, Ford, VW, etc. are great for those who see automobiles as a mode of travel from A-B only. Most of the HEVs sold on the market over the last two decades have left much to be desired in aspects of aesthetics and performance. The 2011 Toyota Auris for example was built in Burnaston, UK [10]. A great HEV offering and built in the UK, this makes it a sustainable choice, yet from a performance vehicle aspect it simply falls short.

\subsection{Government Driven Policy}

\subsubsection{HEV Taxation}

For HEV's registered from April 2017 onwards, the British Government has issued an Alternative Fuel Discount (AFD) which is a $£ 10$ reduction of the First Year Rate (FYR) and the Standard Rate each year after. For new HEV's the greatest benefit comes in the first year in the form of the FYR. The FYR is calculated on tailpipe $\mathrm{CO}_{2}$ emissions, an area where HEV's perform better than ICE vehicles. The true beneficiaries of tax rate savings are the vehicles with emission output of less than $75 \mathrm{~g} / \mathrm{km}$. 
- Vehicles rates equal to or are below $75 \mathrm{~g} / \mathrm{km}$ are $£ 25$ or less, decreasing with respect to emissions levels.

- Vehicles rates above $75 \mathrm{~g} / \mathrm{km}$ are $£ 110$ or more, increasing with respect to emissions levels.

HEV's are considered low emission vehicles, yet only one model on the new market has a $75 \mathrm{~g} / \mathrm{km} \mathrm{CO}_{2}$ output-Toyota Prius 1.8 VVT-I Active Auto [11]. This means the other 29 models will be in the higher cost bracket for the FYR, although they will still be 3-4 bands lower than the respective ICE vehicles and have the $£ 10$ AFD. After the first year, the tax bracket is divided into Standard and Premium, with the latter bracket reserved for vehicles costing $>£ 40,000$.

- The Premium rate is a fixed $£ 465$ for $\mathrm{CO}_{2}$ emissions above $50 \mathrm{~g} / \mathrm{km}$, which all new HEV's are.

- The Standard rate (for $<£ 40,000$ vehicles) is a fixed $£ 150$ [17] for $\mathrm{CO}_{2}$ emissions above $50 \mathrm{~g} / \mathrm{km}$, which all new HEV's are.

- The $£ 10$ AFD does apply to both the Standard and Premium rates for HEV's. So, there is a $£ 10$ saving per annum for HEV's over ICE vehicles after the first year also.

The greatest savings, therefore, are through HEV's registered between March 2001 to March 2017. Alternative Fuel Vehicles (AVF), of which an HEV is, receive a $£ 10$ reduction, and since the tax rate is only calculated by vehicle $\mathrm{CO}_{2}$ emissions, the HEV's generally sit 3-4 VED bands lower than their ICE counterparts, generating a substantial saving each year. Further to this, the lowest VED band is from $\mathrm{CO}_{2}$ emissions of up to $100 \mathrm{~g} / \mathrm{km}$, which many HEV's meet, and the AFV rate is $£ 0$. As shown in Fig. 27.3, there is a considerable hike in cost between VED Band C and D, since many HEV's fall into Band $\mathrm{C}$ or lower, the savings are considerable over the ICE vehicles which are often Band D or higher [11].

\begin{tabular}{|c|c|c|c|}
\hline \multicolumn{4}{|c|}{ 12-month VED rates for cars registered from 01 March 2001 to 31 March 2017 } \\
\hline VED Band & \begin{tabular}{|l|} 
Vehicle \\
CO2 emissions
\end{tabular} & \begin{tabular}{|l} 
Standard rate \\
$2019-20$
\end{tabular} & \begin{tabular}{|l|} 
AFV rate"- \\
2019.20
\end{tabular} \\
\hline A & Up to $100 \mathrm{~g} / \mathrm{km}$ & EO & $\mathrm{E}_{0}$ \\
\hline B & $101-110 \mathrm{~g} / \mathrm{km}$ & $£ 20$ & $\$ 10$ \\
\hline c & $111-120 \mathrm{~g} / \mathrm{km}$ & $£ 30$ & $£ 20$ \\
\hline D & $121-130 \mathrm{~g} / \mathrm{km}$ & $£ 125$ & ₹115 \\
\hline E & $131-140 \mathrm{~g} / \mathrm{km}$ & £145 & £135 \\
\hline $\mathrm{F}$ & $141-150 \mathrm{~g} / \mathrm{km}$ & $£ 160$ & $£ 150$ \\
\hline G & $151-165 \mathrm{gkm}$ & $£ 200$ & $£ 190$ \\
\hline H & $166-175 \mathrm{~g} / \mathrm{km}$ & $£ 235$ & $£ 225$ \\
\hline 1 & $176-185 \mathrm{gkm}$ & $£ 260$ & $£ 250$ \\
\hline $\mathrm{J}$ & $186-200 \mathrm{~g} / \mathrm{km}$ & $£ 300$ & $£ 290$ \\
\hline $\mathrm{K}^{*}$ & $201-225 \mathrm{~g} / \mathrm{km}$ & $£ 325$ & £315 \\
\hline L & $226-255 \mathrm{~g} / \mathrm{km}$ & $£ 555$ & $£ 545$ \\
\hline M & Over $255 \mathrm{~g} / \mathrm{km}$ & $£ 570$ & $£ 565$ \\
\hline
\end{tabular}

Fig. 27.3 The current VED rates for Mar '01-Mar '17 vehicles [11] 


\subsubsection{Alternative Fuel Vehicle Initiatives}

Until October 2018, there was a Plug-In grant for PHEV's and EV whereby a subsidy was available for buyers of these vehicles. Although not available to HEV's due to their very limited range in Zero-emissions mode (Electric Only), this initiative showed that the British Government supported Hybrid-Electric vehicles as a sustainable transport method. However as of October 2018, the grant was changed to support only EV's, with no PHEV support. This decision came about because research suggested that many of the PHEV's were not actually being plugged in and charged. The Government saw this as undermining the incentive and the environmental benefits [12]. Essentially, a PHEV that is not plugged in, acts just like a HEV, and since the Government is no longer supporting the PHEV because of this- the support for HEV could be questioned.

\subsubsection{Green Initiatives}

In 2008 the UK Government brought in the Climate Change Act. Along term, legally binding climate change reduction legislation. The Act laid a framework for emissions reductions and established five-year 'carbon budgets' up to 2050 [13]. Through this, the UK became the first major economy across the globe to pledge the reduction of its contribution to climate change and global warming by 2050 in a legally binding contract. In 2015, the UK entered into The Paris Agreement, a policy spearheaded by the United Nations Framework Convention on Climate Change (UNFCC). This was truly a global initiative developed to hold the increase in global average temperature to below $2{ }^{\circ} \mathrm{C}$ above pre-industrial temperatures and aim to limit global warming to just $1.5^{\circ} \mathrm{C}$. Signed by 160 countries, this marked the turn in environmental awareness and impact. From this, the UK agreed on a target of $40 \%$ emissions reductions from 1990 levels, by 2030 [13]. As of 2019, the UK surpassed the target of the Paris Agreement, with a $42 \%$ reduction in emissions, 11 years ahead of schedule. This led to the decision to revise the Climate Change Act of 2008, and on 27th June 2019, the UK have pledged to end it's contribution to climate change by 2050 . The legally binding contract lays out a target that by 2050 , the UK's net emissions will be zero [14].

For the UK to meet this target, the transport sector and respectively the automotive sector will need to be zero-emissions come 2050. Simply stated, this cannot be met through the use of HEV's or PHEV's. Both hybrid types have an onboard ICE and therefore produce tailpipe emissions. This is a topic of debate that is currently ongoing in government, specifically amongst the Business, Energy and Industrial Strategy Committee (BEISC) and the Committee on Climate Change (CCC). Stated in the Electric Vehicles: driving the transition (fourteenth Report of Session 2017-2019) document provided to the House of Commons, the CCC advised that only BEV and long-range PHEV's should be eligible for sale 2035 onwards [15]. The idea is that 
the majority of all vehicle trips can be completed without an ICE. There is quite some inconsistency reported in the document however as to whether the HEV will be covered by the 'conventional' vehicle phase out or not, since it cannot be plugged in. The 'conventional' vehicle phase out requires the ban of these vehicles by 2040 , which if HEV's are to be considered in this group, would spell the demise of the HEV within the next 20 years. Ultimately, there is still a very ambiguous and unclear decision on whether to phase out HEV's or not, but for the Government to meet it's Zero-Emissions target, the HEV without plug in option is not compatible with this commitment. If a ban on HEV's is not imposed by 2040, the target of only allowing the cleanest new vehicles to the market at that time will be undermined [15].

\subsection{What Is the Future for the HEV?}

During the phase out of the 'conventional' vehicle, HEV included or not, the HEV and PHEV will play an integral part as a stop gap between the removal of pure ICE cars and the dominion of the EV. Many manufacturers are committed to the removal of ICE vehicles from the roads yet support the Hybrid platform as a means of longterm emissions reductions - albeit not cutting emissions to zero. It is clear that for the Government to meet the 2050 target of net zero-emissions, the HEV will not be a long-term solution. However, with very limited infrastructure across the UK to support EV's, the HEV holds an important role of providing a more sustainable option over traditional ICE vehicles. Until the infrastructure is in place for EV's, HEVs and PHEVs can provide transitional technology that alleviates the common 'range anxiety' of prospective and/or current EV owners. Infrastructure is not the only part that will improve for the EV, battery technology is progressing fast, allowing increasing ranges of EV's. The pressure from Governments like the UK's, forces manufacturers to invest in the research and development, benefiting HEVs, PHEVs and EVs [15].

\subsubsection{The Effect of Brexit}

Leaving the EU would result in a change to how the carbon budget in the UK is delivered. With severed ties, any previous agreements on policy will no longer apply or at the very least will be severely weakened. The UK Government will need to replace these with policies of their own since the needs to tackle global warming does not waiver [13]. The UK is world leading in the strive for net zero emissions, and although Brexit looms overhead, the result should not ultimately affect the UK's path towards this goal. However, for the consumer, Brexit does leave a continued uncertainty around exiting the EU and this has affected vehicle sales. There is a growth in Hybrid and Electric vehicle sales, which shows consumers are keen on the new technology, however, a lack of consumer confidence caused by Brexit leaves 
the automotive market soft. In October 2019, a $6.7 \%$ fall in new car sales was seen compared to 12 months prior, with the general election, due 12th December and as 2019 draws to a close, this is unlikely to improve [9].

\subsubsection{Issues and Limitations}

Although HEV's offer a serious potential for consumers to decrease their carbon footprint and environmental impact, there is a fundamental flaw. Many of the HEV's rely on regenerative braking to recharge the batteries, unlike PHEV's with the option to charge off the mains, the HEV requires journeys with a lot of deceleration. In urban driving, this is often true, with a lot stop-start in traffic. However, on long haul motorway journeys, the braking is reduced considerably and often the vehicle does not fully recharge its batteries. The result is that high potential fuel savings reduce to the levels of ordinary ICE powered vehicles, a major consideration for prospective buyers [4].

As the UK's environmental awareness improves, so does the number of AFVs on the road. The servicing and maintenance network for HEV's is therefore diversifying and moving away from only franchised dealers and manufacturers. However, there are still limited capabilities across the UK, and this is a factor to be aware of for prospective buyers. With the new hybrid systems, far higher voltages are present, and offer a serious threat of injury for untrained technicians. This means that not only is the technology different and the garages may not be familiar with the various systems, but a higher danger level is present, and some garages may not be comfortable with these vehicles [16]. Training and specialist equipment are therefore necessary and it's important that any garage the customer takes their HEV to is competent to carry out the required work - this could be a limiting factor for prospective buyers of secondhand HEV's who aren't covered by the dealership and haven't access to a suitable maintenance provider.

\subsection{Conclusion}

The current government policies do not really support the HEV as a sustainable mode of transport and the Tax savings are limited. It is clear than by 2040 at least, the HEV without plug in ability will be phased out. Although, no specific decision has been made on this, for the UK government to meet it's emissions target, this will have to be the case. There is however 20 years between now and 2040, a long time in respect to vehicle ownership. It is important that everyone tries where they can to reduce their impact on the environment, and with the current HEV models, although limited, there are some very good vehicles. The HEV is not future proof, nor is it wholesomely supported by any UK Government initiatives, however the 
HEV provides huge fuel savings and low emissions output. This makes them a very real option, and for the enthusiast, the performance of the electric motor is hard to beat.

\section{References}

1. BEIS, Clean Growth Strategy: executive summary. Retrieved from GOV.UK (2018)

2. EEA, Co2 emissions from cars: facts and figures (infographics). Retrieved from European Parliament (2019)

3. A. Smith, D. Moss, A brief history of hybrid and electric vehicles-picture special. Retrieved from Autocar (2013). https://www.autocar.co.uk/car-news/frankfurt-motor-show/ brief-history-hybrid-and-electric-vehicles-picture-special

4. R. Dredge, Hybrid cars explained. Retrieved from hpi (2017). https://www.hpi.co.uk/content/ electric-cars-the-electric-era/hybrid-cars-explained/

5. EPA, Fuel Economy Compare. Retrieved from Fueleconomy.gov (2019), https://www.fuelec onomy.gov/feg/noframes/18605.shtml

6. E. Loveday, Toyota Prius eclipses 200,000 total sales in Europe, doubling mark set in 2008. Autoblog Green, 50-52 (2010)

7. ICCT, European Vehicle Market Statistics. EU Pocketbook, 81-107 (2016)

8. C. Brand, C. Cluzel, J.L. Anable, Modeling the uptake of plug-in vehicles in a heterogeneous car market using a consumer segmentation approach. Transp. Res. Part A Policy Practice 97, 121-136 (2017)

9. P. Campbell, Electric and hybrid car sales jump to 10 per cent of UK total. London, London, United Kingdom (2019)

10. just-auto.com, UK: Toyota prepares for hybrid production. Retrieved from justauto.com (2010). https://www.just-auto.com/news/toyota-prepares-for-hybrid-production_i d104353.aspx

11. C. Lilly, Car Tax Bands 2019/20. Retrieved from Next greencar (2018). https://www.nextgreen car.com/car-tax/bands/\#q2

12. J. Holder, Exclusive: Government won't reinstate plug-in hybrid grants. Retrieved from Autocar.co.uk (2019). https://www.autocar.co.uk/car-news/industry/exclusive-governmentwont-reinstate-plug-hybrid-grants

13. CCC, Legal duties on climate change. Retrieved from Committe on Climate Change (2018). https://www.theccc.org.uk/tackling-climate-change/the-legal-landscape/

14. DBEIS, UK becomes first major economy to pass net zero emissions law. Retrieved from gov.uk (2019), https://www.gov.uk/government/news/uk-becomes-first-major-economy-to-pass-netzero-emissions-law

15. BEISC, Electric Vehicles: driving the transition (House of Commons, London, 2018)

16. HSE, Electric and hybrid vehicles. Retrieved from HSE.gov.uk (2019). http://www.hse.gov. $\mathrm{uk} / \mathrm{mvr} / \mathrm{topics} /$ electric-hybrid.htm

17. Vehicle Tax Rates (2020, 08 21). https://www.gov.uk/vehicle-tax-rate-tables 
Open Access This chapter is licensed under the terms of the Creative Commons Attribution 4.0 International License (http://creativecommons.org/licenses/by/4.0/), which permits use, sharing, adaptation, distribution and reproduction in any medium or format, as long as you give appropriate credit to the original author(s) and the source, provide a link to the Creative Commons license and indicate if changes were made.

The images or other third party material in this chapter are included in the chapter's Creative Commons license, unless indicated otherwise in a credit line to the material. If material is not included in the chapter's Creative Commons license and your intended use is not permitted by statutory regulation or exceeds the permitted use, you will need to obtain permission directly from the copyright holder.

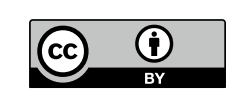

